\title{
Debating when to call cancer by its name
}

\author{
Cite as: CMAJ 2019 April 29;191:E483-4. doi: 10.1503/cmaj.109-5737
}

Posted on cmajnews.com on Apr. 10, 2019.

ancer. A diagnosis that terrifies patients and their families; a term that can be unnerving even for physicians. When cancer becomes part of the conversation, patients feel threatened, anxiety levels skyrocket, and imaginations jump to worst-case scenarios.

That assumption formed the basis for a recent debate in BMJ. A surgeon and breast cancer oncology specialist argued that relabelling ultralow risk tumours to avoid the word cancer would spare patients psychological trauma and make it easier for physicians to de-escalate treatment when appropriate. A histopathologist countered that using alternate names could cause confusion and the answer was better education.

"The debate over the word 'cancer' really boils down to a debate about the art of medicine - how we communicate, both verbally and nonverbally, when we speak with patients," says Dr. Isaac Bogoch, a general internist and infectious disease physician at Toronto General Hospital. "I believe we should always be using the correct term, even if the correct term includes the word 'cancer."'

Discussion among his colleagues has focussed not on whether to use the word "cancer," but on how best to relay important information in a way that's transparent, respectful and understandable to create an environment of trust and clarity.

The word "cancer" holds a lot of power. But so, too, do the thousands of other words doctors use in conversations with patients. "We need to be better as communicators," said Bogoch. "We need to always be setting the stage, so our patients are informed about the possibilities and next steps."
Indeed, using the word "cancer" can be empowering, according to Rosana Faria, a clinical psychologist at St. Mary's Hospital Center in Montreal. "There is this idea that saying 'cancer' might generate anxiety and depression, but that's not necessarily the case," said Faria. "In the long run, information is power, and patients feel better if they know they are receiving full and accurate information."

Though he comes at the debate from a different angle, clinical ethicist Brendan Leier reaches the same conclusion. In Canada, the standard for consent is a rigorous one, with a number of legal cases making it clear that the burden of responsibility for a patient's understanding falls on the physician. Using euphemisms or overly technical language both risk muddying the waters.

If patients are going to provide informed consent - to map what their doctors are

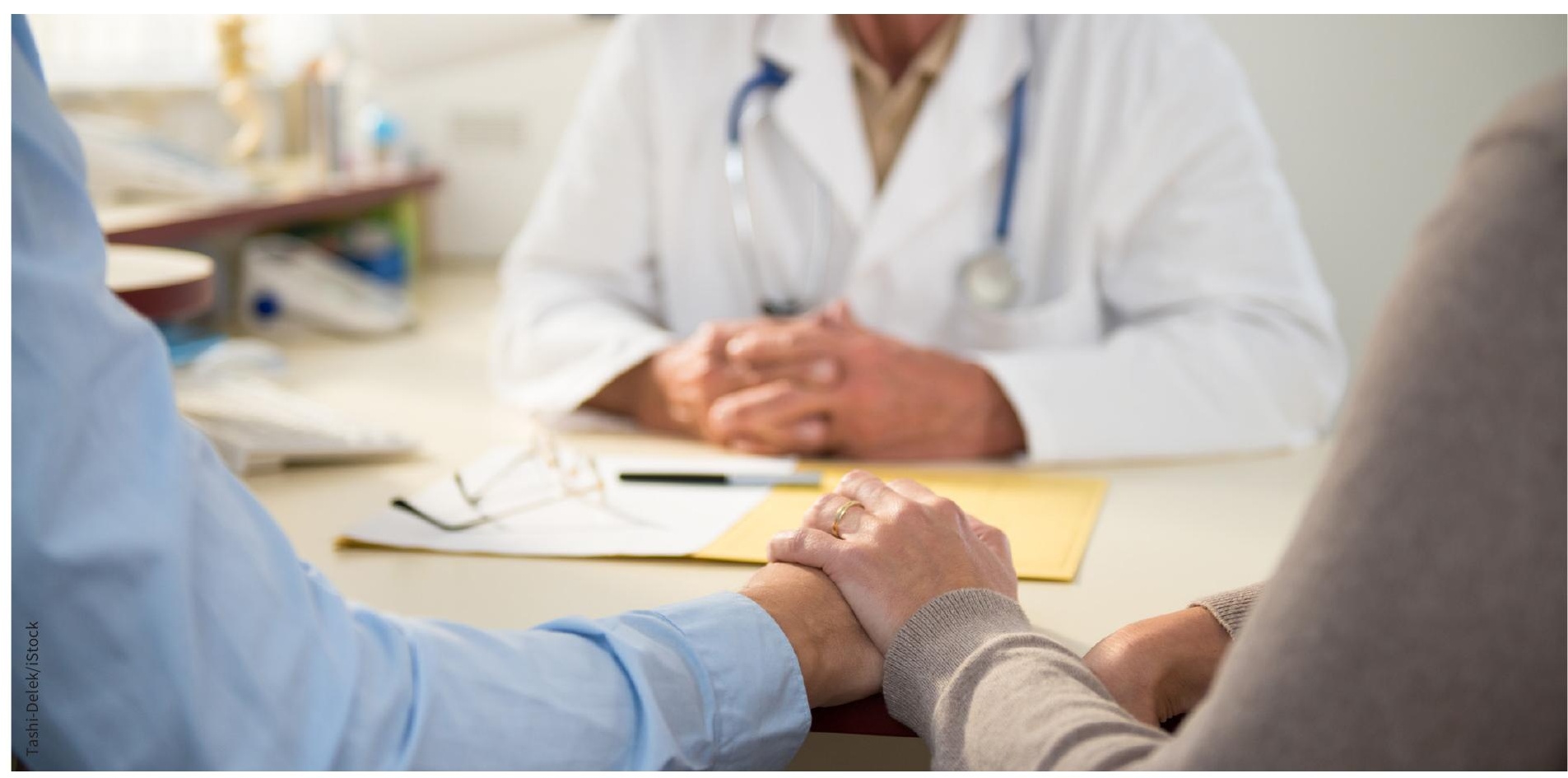

Physicians must balance sensitivity with clarity when delivering a diagnosis. 
telling them into their lives in a meaningful way - they have to be very clear on what their doctors are saying, said Leier, who works out of the John Dossetor Health Ethics Centre in Alberta. "If respect for autonomy is the value, consent is the tool. It is the instrument that allows us to get to the heart of the matter. So when we're talking about individuals, that's very important."

Leier said he encountered the best example of this important lesson not as a clinical ethicist but when he was working his way through school as a bartender. One night, a regular customer got into a fight at the bar and ended up getting punched in the mouth. Weeks later, the man stopped by the bar again. He told Leier that he had been a brass player, studying music at the university, but had to drop out because he'd lost feeling in one half of his lip since the fight and subsequent treatment in an emergency room.

"Obviously, you can't ask everyone coming into ER if they play a brass instrument, but it really illustrates how impor- tant the process of consent is," said Leier. If the resident in the ER who treated the man had mentioned there was risk of nerve damage, the musician may have opted for a surgical specialist. For most people, losing a bit of feeling in a lip would be no big deal, but for this man it had major consequences. "It all comes down to: You can never appropriately assume anything - you don't know people's lives or how they'll assess risk."

Sarah Brown, Ottawa, Ont. 